\title{
PENGEMBANGAN METODE PEMBELAJARAN HURUF HIJAIYAH DENGAN SMARTPHONE ANDROID
}

Edi Junaedi ${ }^{1}$, Fithri Wulandari ${ }^{2}$

1,2 Teknik Informatika, Sekolah Tinggi Teknik Multimedia Cendekia Abditama

Jl. Islamic raya kelapa dua komplek pendidikan tinggi Islamic village

E-mail: ${ }^{1}$ edi@cendekia.ac.id, ${ }^{2}$ fithri@cendekia.ac.id

\begin{abstract}
Abstrak
SDIT Al-Istiqomah II Kota Tangerang adalah Sekolah Islam Terpadu yang terletak di Perumnas Kota Tangerang. Pelajaran huruf hijaiyah adalah salah satu pelajaran wajib bagi SDIT Al-Istiqomah, namun kurangnya guru adalah masalah utama pada SDIT AlIstiqomah. Masalah ini memiliki dampak yang cukup besar bagi pemahaman murid dalam memahami materi di SDIT Al-Istiqomah khususnya di bidang Pembelajaran huruf hijaiyah. Setidaknya durasi guru untuk membuat murid belajar huruf hijaiyah sangat minim karena mempelajari materi harus dilakukan secara intensif. Oleh sebab itu dibutuhkannya sebuah aplikasi android untuk memudahkan murid dalam belajar huruf hijaiyah. Penelitian ini dilakukan dengan mengkombinasikan masukan dari berbagai pihak seperti dosen, narasumber, dan institusi lain. Metode dalam penelitian rancang bangun aplikasi pembelajaran huruf hijaiyah ini peneliti menggunakan model SDLC Waterfall. Yaitu metode yang digunakan adalah enam tahapan di antaranya: Sistem planing, analisis kebutuhan perangkat lunak, desain, coding, pengujian dan pemeliharaan, selain itu peneliti juga melakukan beberapa tahapan yaitu: diskusi dan koordinasi, pengumpulan data dan bahan ajar termasuk penggunaan Al-Quran, buku Iqro dan media internet, pembuatan aplikasi, diseminasi internal, publikasi ilmiah, serta pelaporan penelitian. Tujuan dari penelitian ini adalah dapat menghasilkan suatu media pengajaran berbasis teknologi pembelajaran huruf hijaiyah yang interaktif dan mudah digunakan sehingga proses pembelajaran akan lebih menarik dan mudah dipahami, serta dapat mendorong lembaga pendidikan untuk memanfaatkan teknologi sebagai media pembelajaran yang interaktif dan menyenangkan. Hasil dari penelitian ini yaitu aplikasi media pembelajaran huruf hijaiyah dengan smartphone android dan media pembelajaran yang mudah dan layak digunakan.
\end{abstract}

Kata kunci - Metode Pembelajaran; Huruf hijaiyah; Smartfone; Android; SDLC.

\begin{abstract}
SDIT Al-Istiqomah II Tangerang is an Integrated Islamic School located in Perumnas Kota Tangerang. Hijaiyah letter lessons are one of the compulsory lessons for SDIT AlIstiqomah, but the lack of teachers is the main problem at SDIT Al-Istiqomah. This problem has a large enough impact on students' understanding in understanding the material in SDIT Al-Istiqomah, especially in the field of learning hijaiyah letters. At least the teacher's duration for getting students to learn hijaiyah letters is very minimal because studying the material must be done intensively. Therefore we need an android application to make it easier for students to learn hijaiyah letters. This research was conducted by combining input from various parties such as lecturers, resource persons, and other institutions. The method in this research on the design of the hijaiyah letter learning application, researchers used the SDLC Waterfall model. Namely, the method used is six stages including: System planing, software needs analysis, design, coding, testing and maintenance, besides that researchers also carry out several stages, namely:
\end{abstract}


discussion and coordination, data collection and teaching materials including the use of the Al-Quran, Iqro books and internet media, application development, internal dissemination, scientific publications, and research reporting. The purpose of this research is to be able to produce a teaching media based on hijaiyah letter learning technology that is interactive and easy to use so that the learning process will be more interesting and easy to understand, and can encourage educational institutions to use technology as an interactive and fun learning medium. The results of this study are the hijaiyah letter learning media application with an android smartphone and learning media that are easy and feasible to use.

Keywords - Learning Methods; Hijaiyah letters; Smartfone; Android; SDLC

\section{PENDAHULUAN}

SDIT Al-Istiqomah II Kota Tangerang adalah Sekolah Islam Terpadu yang terletak di Perumnas Kota Tangerang. Pelajaran huruf hijaiyah adalah salah satu pelajaran wajib bagi SDIT Al-Istiqomah, namun kurangnya guru adalah masalah utama pada SDIT Al-Istiqomah. Masalah ini memiliki dampak yang cukup besar bagi pemahaman murid dalam memahami materi di SDIT Al-Istiqomah khususnya di bidang huruf hijaiyah. Setidaknya durasi guru untuk membuat murid belajar huruf hijaiyah sangat minim karena mempelajari materi harus dilakukan secara intensif. dan juga ketika guru ada halangan tidak bisa mengajar murid yang sudah berangkat terpaksa harus pulang kembali dengan sia-sia karena yang mengajar tidak ada. Melihat begitu pentingnya pembelajaran Huruf hijaiyah dalam belajar membaca Qur'an sehingga perlunya solusi dalam mengatasi permasalahan tersebut. Oleh sebab itu perlu adanya pempelajaran mandiri di SDIT Al-Istiqomah sebagai tambahan untuk mengatasi mengatasi masalah pembelajaran huruf hijaiyah di dalam AlQuran, pempelajaran mandiri ini mengembangkan aplikasi berbasis teknologi informasi dengan memanfaatkan perangkat handphone yang dapat dilakukan dimana saja dan kapan saja bila di perlukan agar murid-murid paham dan lancar dalam membaca Alquran dengan tartil.
Tujuan utama dari dilakukannya penelitian ini adalah untuk membuat aplikasi media pembelajaran huruf hijaiyah dengan memanfaatkan smartfone android guna mendukung proses pembelajaran pada SDIT Al-Istiqomah II Kota Tangerang, sehingga proses pengajaran akan lebih interktif dan menyenangkan. Dengan menggabungkan perkembangan teknologi dalam proses pembelajaran ini maka diharapkan akan memberikan pengalaman belajar kepada siswa/i SDIT Al-Istiqomah lebih aktif dan menyenangkan.

\section{METODE PENELITIAN}

Dalam penelitian pengembangan metode pembelajaran huruf hijaiyah ini peneliti menggunakan model SDLC Waterfall. Yaitu metode yang digunakan adalah enam tahapan di antaranya: Sistem planing, analisi kebutuhan perangkat lunak, desain, coding, pengujian dan pemeliharaan.[11] Selain itu peneliti juga memerlukan kordinasi dari berbagai elemen pendukung pengembangan aplikasi pembelajaran ini tentunya juga akan mengintegrasikan beberapa bagian antara lain: Guru, siswa, peneliti dan laboratorium teknik informatika.

Secara umum gambaran keterhubungan antara tiap bagian tersebut dapat dilihat pada gambar 3.1. 


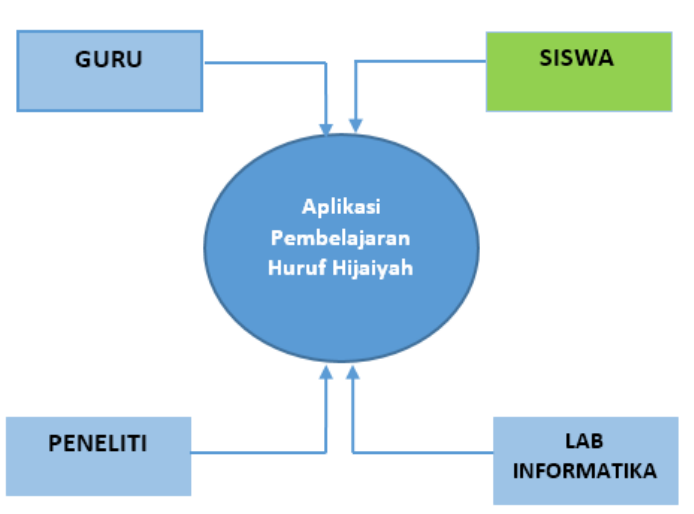

Gambar 1: Alur Hubungan Antar Bagian dalam Pembuatan Pembelajaran huruf hijaiyah

Guru merupakan bagian yang bertanggung jawab untuk menentukan mata pelajaran/ materi pelajaran apa saja yang perlu divisualkan dan diimplementasikan pada aplikasiPembelajaran Huruf hijaiyah. Tim peneliti akan berkoordinasi dengan guruguru pengampu masing-masing mata pelajaran untuk menentukan materi apa saja yang akan dijadikan bahan/ konten dalam aplikasi Pembelajaran huruf hijaiyah.

Siswa sebagai tujuan dilakukannya penelitian ini diharapkan dapat memperoleh manfaatnya dalam menggunakan aplikasi pembelajaran huruf hijaiyah. Dengan pengembangan aplikasi Pembelajaran Huruf hijaiyah ini siswa diharapkan dapat lebih termotivasi dalam belajar dan mudah memahami pembelajaran huruf Qur'an.

Laboratorium dalam hal ini adalah sebagai penunjang kegiatan penelitian. Dalam penelitian ini, peneliti menggunakan laboratorium informatika sebagai ruang kerja dalam pengembangan aplikasi pembelajaran huruf hijaiyah. Peneliti dalam hal ini memeliki peranan penting dalam melakukan koordinasi ke semua elemen terkait. Peneliti akan berkoordinasi dengan guru sebagai elemen yang memberi masukan mengenai konten/ mata pelajaran apa saja yang membutuhkan untuk aplikasi pembelajaran Huruf hijaiyah.

Dibutuhkan beberapa tahapan dalam melaksanakan penelitian ini sampai pada akhirnya aplikasi pembelajaran Huruf hijaiyah ini dapat digunakan dalam proses pembelajaran. Tahapan-tahapan tersebut adalah sebagai berikut.

1. Diskusi dan koordinasi dengan bagian akademik sekolah, guru, dan narasumber.

Sebagai tahap awal penelitian diskusi dan koordinasi dengan bagian akademik sekolah, guru pengajar dan narasumber sangatlah diperlukan. Kegiatan ini ditujukan untuk meninjau kecocokan dengan aplikasi pembelajaran Huruf hijaiyah.

2. Pengumpulan Data dan Materi Ajar Pada tahap ini, peneliti mengumpulkan data mata pelajaran dan materi ajar yang akan dijadikan sebagai konten dalam pengembangan pembelajaran huruf hijaiyah.

3. Pembuatanaplikasi pembelajaran Huruf hijaiyah

Tahapan ini merupakan tahapan inti dari penelitian. Pemebuatan media pembelajaran berbasis aplikasi Huruf hijaiyah dilakukan dengan mengacu pada hasil-hasil yang telah dicapai dan dirumuskan pada tahap-tahap sebelumnya.

\section{HASIL DAN PEMBAHASAN}

1.1. Pembahasan Pengembangan Media

a. Analisis Masalah

Kegiatan dan proses untuk menghasilkan suatu produk media pembelajaran yang layak dan mudah digunakan untuk pembelajaran makharijul huruf hijaiyyah, diawali dengan Persiapan awal yang dilakukan dengan observasi awal untuk identifikasi masalah, melalui wawancara dengan guru Qur'an Hadits dan beberapa Ustadz di SD-IT AlIstiqomah II Kota Tangerang. Tahap 
pertama yang dilakukan yaitu mengidentifikasi masalah yang ada sebagai studi kelayakan dan analisis kebutuhan dari sistem yang akan diterapkan.

b. Analisis Kebutuhan Sistem

Analisi kebutuhan dalam pengembangan metode pembelajaran ini ada dua yaitu kebutuhan fungsional dan kebutuhan non fungsional. Kebutuhan fungsional adalah software dan hardware yang digunakan yaitu: laptop ASUS VivoBook S14, dengan sistem operasi windows 10, RAM 8GB dan SSD 500GB, kemudian software lain yang diperlukan adalah Java, Android Studio Sebagai perangkat lunak Desain. Sedangkan analisis kebutuhan fungsional adalah bagian paparan mengenai fitur-fitur yang akan dimasukkan kedalam aplikasi yang akan dibuat.

\subsection{Desain}

Tahapan selanjutnya ialah proses desain dan pembuatan aplikasi pembelajaran makhrojul huruf Qur'an sesuai dengan gambar dan memberikan warna atau tekstur. Bagian ini meliputi pembuatan desain layout yang mendukung semua informasi yang akan disajikan, membuat teks sebagai penyampaian pesan dan lainnya.

a. Perancangan Use case Diagram

Usecase Diagram merupakan suatu aktifitas yang menggambarkan urutan interaksi antar satu atau lebih aktor dan sistem. Diagram ini memperlihatkan himpunan Use-Case dan Actor-Actor (jenis khusus dari kelas). Diagram ini penting untuk mengorganisasi dan memodelkan perilaku dari suatu sistem yang dibutuhkan serta diharapkan pengguna. Usecase yang akan di rancang yaitu Usecase diagram untuk pengaksesan melalui perangkat android gambar 3. di bawah ini menjelaskan aliran Usecase diagram pengaksesan melalui perangkat android.[2].

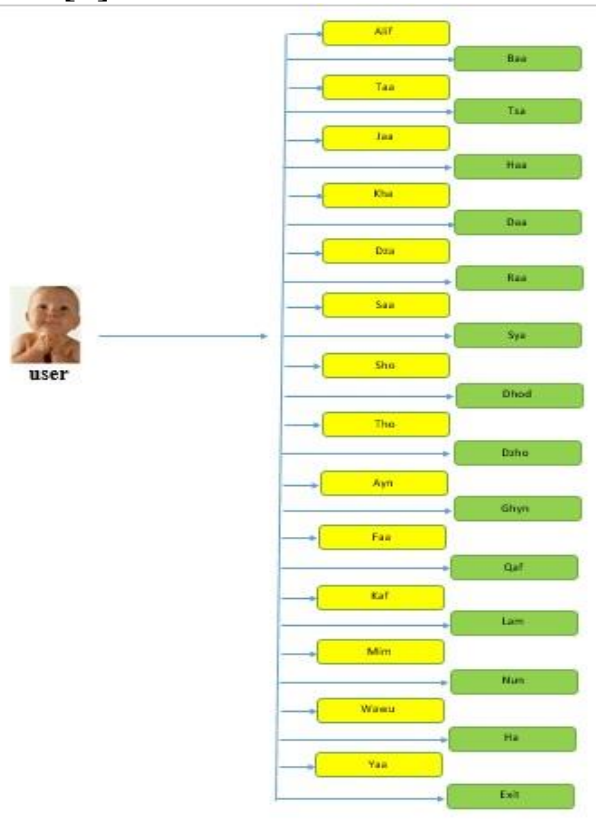

Gambar 3.1 Model Usecase Diagram Usecase Diagram ini menggambarkan hubungan pengguna (user) dengan aplikasi yang berisi cara-cara dalam pengaksesan huruf Qur'an.

b. Rancangan Activity Diagram Activity Diagram adalah alur kerja pada setiap usecase. Activity diagram pada analisa mencakup activity setiap usecase. Diagram ini merupakan tipe khusus dari diagram state yang memperlihatkan aliran suatu aktifitas lainnya dalam suatu sistem. Diagram ini penting dalam pemodelan fungsi-fungsi dala suatu sistem dan member tekanan pada aliran kendali antar objek. 


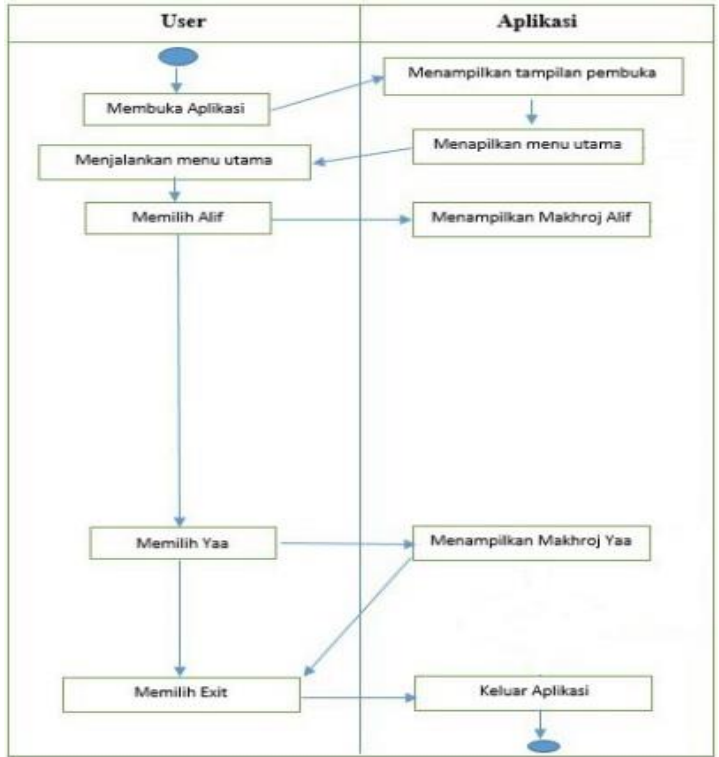

Gambar 3.2 Model Activity Diagram

Model activity Diagram adalah gambaran aktivitas user saat menggunakan aplikasi. Dimulai dari membuka aplikasi sampai menampilkan tampilan pembuka, menampilkan menu utama kemudian menjalankan menu utama tampilan keluar aplikasi.

\section{c. Coding}

Rancangan aplikasi yang sudah didesain setelah itu lakukan pengaturan dan koding di Script untuk menjalankan beberapa fungsi aplikasi. Aplikasi Makhorijul Huruf Qur'an Berbasis Android ini terdiri dari beberapa halaman interface, antara lain: splash screen, menu utama, sub menu yang berisi materi, latihan soal, tentang, bantuan, dan keluar.

\section{d. Pengujian}

Setelah aplikasi berhasil dibuat, dilakukan tes baik dari perangkat Android secara langsung maupun menggunakan simulator.[1] Jika ditemukan kekurangan atau bug maka akan segera diperbaiki. Jika tidak terdapat error maka aplikasi dapat dilakukan build.

A. Tampilan awal aplikasi

Tampilan awal aplikasi adalah merupakan tampilan yang pertama muncul ketika aplikasi pertama kali di buka.[7]

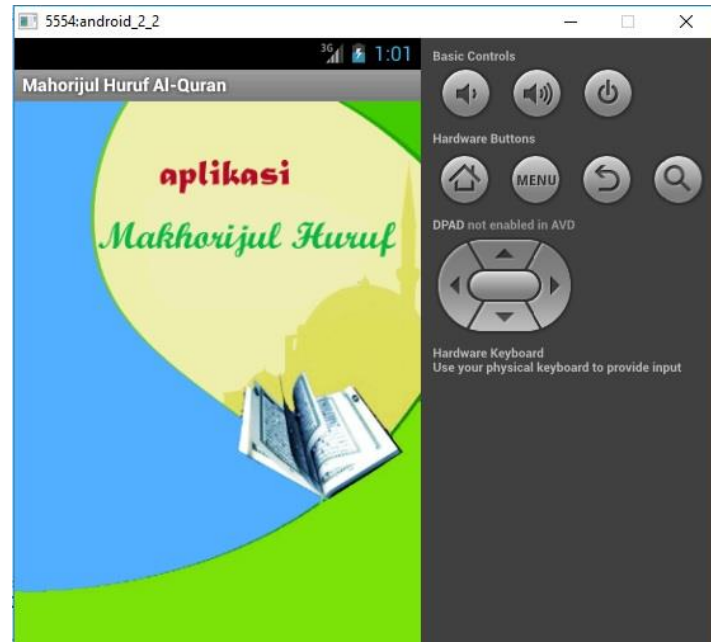

Gambar 3.3 Tampilan Awal Aplikasi (makhorijul huruf)

B. Tampilan Utama Aplikasi

Menu utama adalah tampilan yang muncul setelah tampilan awal aplikasi dan adanya terdapat beberapa tombol utama seperti gambar di bawah ini:

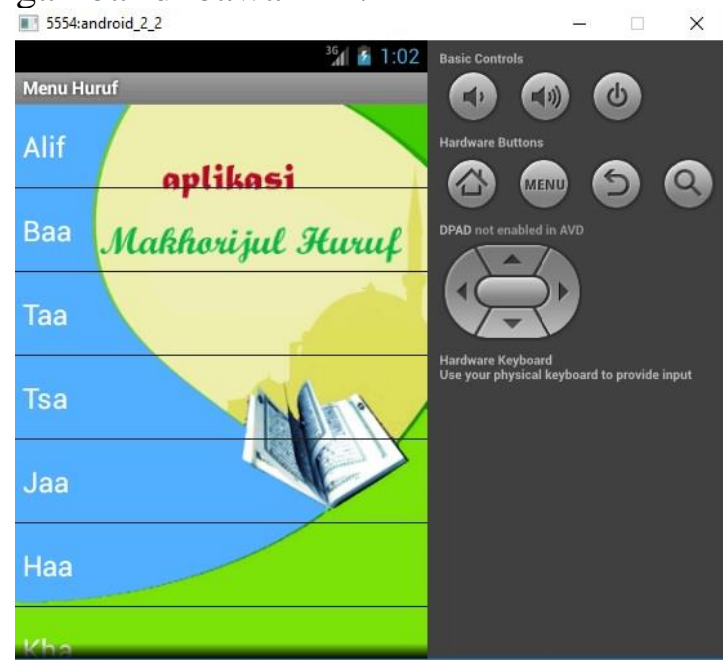

Gambar 3.4 Tampilan Utama Aplikasi (makhorijul huruf)

e. Tampilan Materi Aplikasi

Berikut ini merupakan tampilan materi latihan makhroj huruf quran dengan mengeklik tombol latihan alif yang ada di menu utama dan hasilnya seperti gambar di bawah ini:[6] 


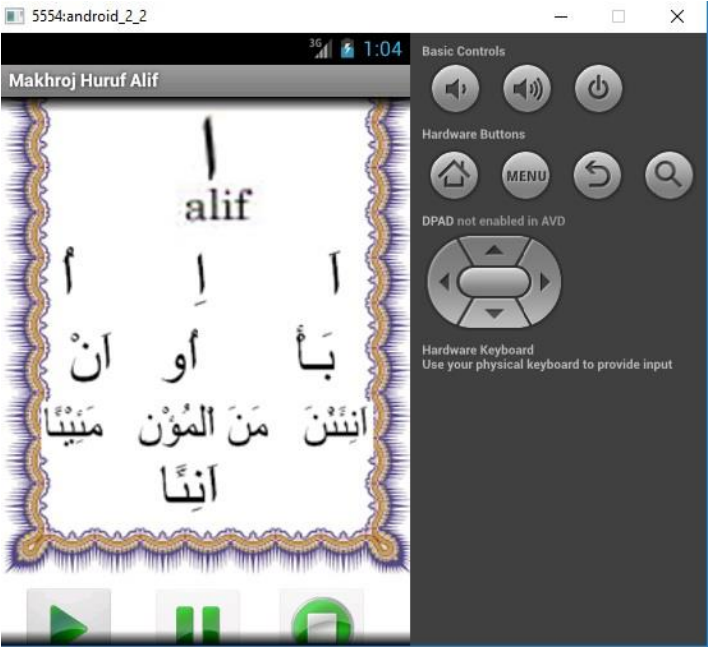

Gambar 3.5 Tampilan Materi Aplikasi (makhrorijul huruf)

\section{f. Tampilan Exit}

Tampilan exit ini untuk memberikan petunjuk agar bisa keluar dari aplikasi yang sudah di pelajari, hingga semua aplikasi tertutup dan kembali lagi seperti semula/ dari awal aplikasi di buka, contoh gambar seperti di bawah ini:

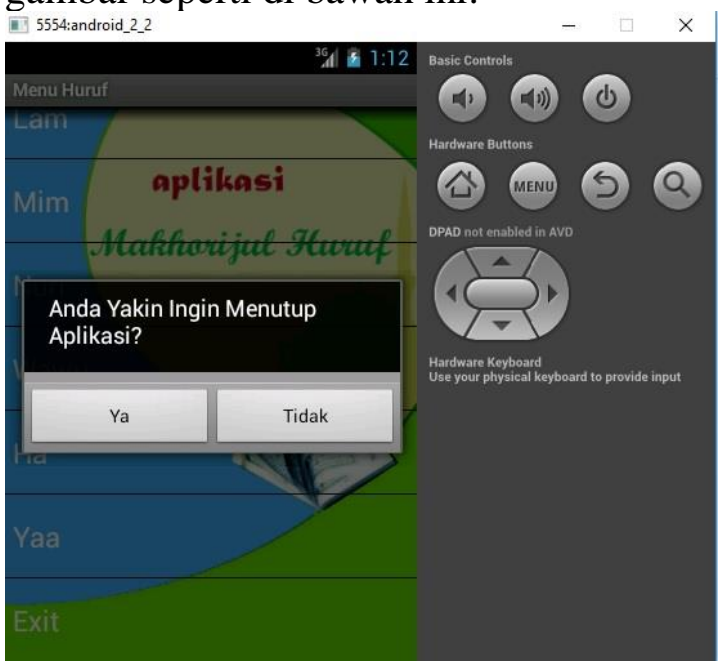

Gambar 3.6 Tampilan Exit

\section{a. Pemeliharaan}

Seiring semakin banyak perangkat Android lain yang menggunakan, maka kemungkinan terdapat bug semakin tinggi. Oleh karena itu dibutukan pemeliharaan setelah aplikasi berhasil dibuat. Hal ini dilakukan agar tetap menjaga aplikasi dapat berjalan dengan baik di setiap perangkat.

\section{KESIMPULAN}

1. Berdasarkan hasil penelitian dan pembahasan pada penelitian ini, maka dapat disimpulkan sebagai berikut:

2. Aplikasi ini dapat membatu memudahkan proses pembelajaran di SD-IT Al-Istiqomah II Kota Tangerang. Aplikasi huruf Qur'an ini berhasil dijalankan di android minimal versi 4.1.2 Jelly bean. Bean).

3. Hasil rancangan analisa dan desain Aplikasi Huruf Qur'an ini berhasil di implementasikan dengan baik. Hal ini ditunjukkan dengan fiturfitur aplikasi yang berjalan dengan baik.

4. Memiliki desain tampilan yang simple dan tidak terlalu rumit bagi pengguna.

b. Saran:

Adapun saran yang dapat diberikan penulis untuk aplikasi ini yaitu :

1. Dikembangakn lagi dalam hal tampilan agar terlihat lebih menarik sehingga menjadi daya tarik tersendiri bagi pengguna aplikasi ini.

\section{DAFTAR PUSTAKA}

[1] Wena, Made. Strategi Pembelajaran Inovatif Kontemporer (Suatu Tinjauan Konseptual Operasional). Jakarta: Bumi Aksara, 2014.

[2] Hamalik, Oemar. Perencanaan Pengajaran Pendekatan Sistem. Bandung: Bumi Aksara, 2001.

[3] Developer, Android. 2017. Mengenal Android Studio, https://developer.android.com/stud 
io/intro/index, Tanggal Akses: 14 Agustus 2019.

[4] Gng, Mr., 2016. "Pengertian Dan Tingkatan Versi Android", http://seputarti.com/android/penge rtian-dan-tingkatan-versiandroid.html, Tanggal Akses: 13 Agustus 2019.

[5] Annuri A. 2013. Panduan Tahsin Tilawah AL-Qur'an \& Ilmu Tajwid. Jakarta: Pustaka AlKautsar.

[6] Saputra, Dian Adriansyah. 2017. "Pengembangan Aplikasi Pembelajaran Makhorijul Huruf hijaiyah Berbasis Animasi". Tesis diakses dari http://repository.umy.ac.id/handle/ 123456789/15182

[7] Nikmah, Siti Nur. 2015. Pengembangan
Pembelajaran Makharijul Huruf Hijaiyyah Berbasis Adobe Flash CS6. Diakses dari http://eprints.walisongo.ac.id/5042 /1/113111142.pdf

[8] Dharwiyanti Sri, Wahono atria Romi, Pengantar Unified Modeling Language (UML), http://www.ilmukomputer.com

[9] Salahudin, 1986. Pengertian Audio Visual Dalam Pembelajaran, PT. Raja Grafindo. Jakarta

[10] H. N. Subhan, Pintar Membaca Al-Quran Tanpa Guru, Jakarta, 2009 Diakses dari: http://journal.stmikglobal.ac.id/

[11] Sukamto, dan M. Shalahuddin. 2018. Rekayasa Perangkat Lunak Terstruktur Dan Berorientasi Objek Edisi REVISI. Bandung: Informatik. 